\title{
Os discursos de ódio na cibercultura
}

SANTOS, Marco Aurélio Moura Dos. O discurso de ódio nas redes sociais. São Paulo: Lura Editorial, 2016.

A datar de sua popularização no Brasil, no meado dos anos 2000, a internet vem contribuindo, substancialmente, nos comportamentos dos sujeitos que compõem a alcunhada sociedade da informação. Esta, têm desencadeado significativas alterações na produção da economia, da cultura e nos modos de interação social. Esse indicativo reflete na vida contemporânea, na qual as mudanças, desde a modernidade até a contemporaneidade, anunciam transformações no comportamento.

O advento das Redes Sociais Digitais possibilitou a transposição de inúmeras formas de interações interpessoais decorrentes da vida offline para vida on-line. Indivíduos reelaboraram constantemente suas formas de se relacionar com o tempo e o espaço, criando novas maneiras de socialização em rede. A interação permitida pelo uso de dispositivos e as potencialidades das Tecnologias de Informação e Comunicação (TICs) tem contribuído para repensar as dinâmicas sociais, de modo que, "[...] pensar a tecnologia, nesta era do pós-digital, significa implicá-la nas táticas e estratégias do poder." (SANTAELLA, 2016, p. 11)

Assim, a criminalidade não é um fenômeno alheio a essas transformações. Como a rede é um espaço de socialização como qualquer outro, mediado por ações de indivíduos que fazem parte dela, a violação dos direitos humanos também ocorre neste espaço, agora com características sofisticadas por meio das tecnologias.

Por oferecer a ilusão do suposto anonimato e por tornar-se um ambiente de rápida veiculação de mensagens com um grande alcance de público, crimes que já eram executados na vida off-line foram transferidos para a vida on-line. Discursos de ódio e discriminatórios relacionados ao gênero, sexualidade, classe social, posicionamento político e religioso, cor e etnia são uma realidade na rede; estes, são caracterizados por "[...] qualquer expressão que desvalorize, menospreze, desqualifique e inferiorize os indivíduos. Trata-se de uma situação de desrespeito social, uma vez que reduz o ser humano à condição de objeto". (SILVEIRA, 2008, p. 80)

Nessa contextura, temos o livro $O$ discurso de ódio em redes sociais (2016), fruto de uma dissertação de mestrado defendida no 
Programa de Mestrado em Direito da Sociedade da Informação das Faculdades Metropolitanas Unidas (FMU/SP). Trata-se de uma obra importante para entender o presente cenário da disseminação do ódio na rede online, assim como suas raízes, conceitos e questões jurídicas.

O livro é composto por cinco capítulos, incluindo introdução e conclusão, no qual o autor retrata os conceitos e elementos acerca do tema, os núcleos do discurso de ódio, o direito a diferença e a identidade e o discurso de ódio, e conclui fazendo uma análise no que concerne a legislação brasileira para crimes de ódio on-line.

$\mathrm{Na}$ introdução, Santos faz uma análise entre o ciberespaço e o discurso de ódio. Ele prossegue afirmando que as TICs, apesar de não ter utilizado esta denominação, possibilitou inúmeras maneiras de disseminação de informações entre sujeitos de lugares e culturas diferentes, formando, assim, uma "cultura participativa". (JENKINS, 2009, p. 30) Contudo, mesmo a rede online sendo fomentadora no que tange a projeção de conhecimento dos indivíduos, também é um ambiente "[...] fértil para a ampliação de aspectos conflituosos de realidade palpável e do relacionamento social, como o ódio e todas suas manifestações". (SANTOS, 2016, p. 8)

No capítulo um, Santos discute os conceitos e elementos do discurso de ódio nas redes sociais na sociedade da informação. Ele faz um levantamento histórico e do pensamento filosófico para mostrar que "o ódio não é uma questão nova na sociedade". (SANTOS, 2016, p. 23) Continua a afirmar que para o entendimento desses discursos presentemente, é fundamental trazer à tona a discussão a respeito da natureza do mal. Para tal, apresenta definições de Freud (século XX), Arendt (1999), Glucksmann (2007) e Brugger (2007), no que tange o ódio e o mal desde a idade média até os dias atuais.

Para fundamentar o ódio, o autor traz André Gluscksmann citado por Santos (2016, p. 20) que declara:

[...] o ódio existe, todos nós já nos deparamos com ele, tanto na escala microscópica dos indivíduos como no cerne de coletividades gigantescas. A paixão por agredir e aniquilar não se deixa iludir pelas magias da palavra. As razões atribuídas ao ódio nada mais são do que circunstâncias favoráveis, simples ocasiões, raramente ausentes, de liberar a vontade de simplesmente destruir. 
Através da definição de Gluscksmann, Santos relata que caracterizar o discurso de ódio é uma tarefa difícil, pois este pode aparecer de forma implícita ou explícita; isto é, a intenção do agressor pode aparecer de maneira clara e objetiva ou subliminar.

Ao refletir sobre o mal, mas precisamente sobre a "banalidade do mal" (ARENDT apud SANTOS, 2016); o autor chega a conclusão de que o mal na atualidade se tornaria algo cotidiano, como um ato qualquer, ou seja, algo banal e disponível a todos, "[...] uma vez que o processo tecnológico atual denominado 'sociedade da informação', não parece a priori, ser capaz de romper com a intolerância enraizada nas relações humanas, muito pelo contrário, parece apontar para a 'banalidade do mal'". (SANTOS, 2016, p. 26)

Ainda no capítulo um, Santos apresenta outros três conceitos: identidade e diferença - através dos estudos de Lévi-Strauss (2010) e Hall (2011); análise do discurso, trazendo as contribuições de Foucault; e redes sociais a partir das definições de Castells (2005) e Recuero (2012).

O conceito de redes sociais aparece sob a ótica de Recuero (apud SANTOS, ano, p. 114) que define como: "[...] agrupamentos humanos, constituídas pelas interações, que constroem os grupos sociais. Nessas ferramentas, essas redes são modificadas, transformadas pela mediação das tecnologias e, principalmente, pela apropriação delas para a comunicação".

Nesse sentido, entende-se que as redes sociais são interações interpessoais que já existiam antes do surgimento e popularização da internet e, após o advento das TICs, foram reformuladas e modificadas, transformando-se em redes sociais digitais.

No capítulo dois, o autor traz os conceitos de intolerância, preconceito e violência, além de trazer uma abordagem jurídica acerca do discurso de ódio, perpassando pelos estudos em relação a dignidade da pessoa humana.

O conceito de intolerância vem frequentemente associado ao preconceito, tornando-os, assim, "conceitos vizinhos", que podem ser definidos como atitudes de hostilidade nas relações pessoais, destinada contra um grupo inteiro ou contra indivíduos pertencentes a ele, e que preenche uma função irracional definida dentro da personalidade. Apresenta-se também a concepção de "intolerância selvagem", de Umberto Eco (apud SANTOS, 2016, p. 131), que é caracterizada com raivosa, descontrolada, inexplicável e impulsiva, ficando nivelada a irracionalidade. 
Tratando-se da definição de violência, ele traz o texto da Lei $n^{0}$ 11.340/2006, em seu Art. 7, que define as formas de violência:

A violência física, ou seja, a que ofenda a integridade ou saúde corporal; a violência psicológica, entendida como qualquer conduta que lhe cause dano emocional e diminuição da auto estima ou que causa prejuízo e perturbe o pleno desenvolvimento ou que vise degradar ou controlar suas ações, comportamentos, crenças e decisões, mediante ameaça, constrangimento, humilhação, manipulação, isolamento, vigilância constante, perseguição contumaz, insulto, chantagem, ridicularizarão, exploração e limitação do direito de ir e vir ou qualquer outro meio que lhe cause prejuízo à saúde psicológica e à autodeterminação; a violência sexual; a violência patrimonial, e ao final a violência moral, entendida como qualquer conduta que configure calúnia, difamação ou injúria. (BRASIL apud SANTOS, 2016, p. 243).

Desse modo, compreende-se que a violência pode ser expressada e sofrida em diversas esferas internas e externas aos sujeitos, podendo ser um produto da natureza, no sentido de que é intrínseca à humanidade; e, para outros, um produto da história, que não é, portanto, natural ao homem.

No capítulo três, Santos aborda a diversidade cultural humana. Para ele, o debate acerca da diferença cultural entre as sociedades que compõem o mundo, a partir das concepções de (STRAUSS apud SANTOS, 2016), demonstra a impossibilidade de avaliar e julgar sociedades com base em instrumentos utilizados em outras sociedades, de forma que somente a própria sociedade poderia refletir sobre si mesma, julgando-se e avaliando-se. Ainda segundo o autor nenhuma cultura possuiria critérios absolutos que permitissem a realização de distinções entre os conhecimentos, crenças, artes, moral, direito, costumes, aptidões ou hábitos dos seres humanos de outras culturas, podendo e devendo fazer tais distinções, contudo, quando se tratasse de suas próprias manifestações culturais.

Nas conclusões, Santos ratifica que os crimes relacionados ao ódio, na esfera off-line e on-line, se transformaram numa questão estatal e sua repreensão reflete a preocupação quanto a influência deste fenômeno na vida social das coletividades.

Assim, não há como considerar os indivíduos como totalmente iguais e situados num espaço tempo fixo, uma vez que o respeito à condição humana aponta para a diversidade da própria condição 
humana. Ademais, o discurso do ódio se volta contra a diversidade humana, fere a atual Constituição Federal e, sobretudo, esgarçam a segurança na internet.

\section{Referências}

JENKINS, Henry. Cultura da convergência. São Paulo: Aleph, 2009.

SANTAELLA, Lucia. Temas e dilemas do pós-digital: a voz da política. 1. ed. São Paulo: Paulus, 2016. v. 1.

SANTOS, Marco Aurélio Moura dos. O discurso de ódio nas redes sociais. São Paulo: Lura Editorial, 2016.

SILVEIRA, Sérgio Amadeu; PRETTO, Nelson de Luca. (org.). Além das redes de colaboração: internet, diversidade cultural e tecnologias do poder. Salvador: Edufba, 2008.

Submetido em 25/03/2019. Aceito em 19/06/2020. 
